\title{
Effects of preanesthetic single administration of dexmedetomidine on the remifentanil and propofol requirement during laparoscopic cholecystectomy
}

Received February 7, 2018

Revised 1st, April 30, 2018 2nd, July 16, 2018 3rd, July 26, 2018 Accepted July 26, 2018

\section{Corresponding author}

Keon Hee Ryu, M.D., Ph.D. Department of Anesthesiology and Pain Medicine, Eulji University Hospital, 95 Dunsanseo-ro, Seo-gu, Daejeon 35233, Korea

Tel: 82-42-611-3655

Fax: 82-42-611-3882

E-mail: ryu4912@naver.com ORCID

https://orcid.org/0000-0001-5781-6658

\section{Han Park, Heung Soo Kim, Jae Won Kim, Gang Geun Lee, Dong Ho Park, Chang Young Jeong, Sun Gyoo Park, and Keon Hee Ryu}

Department of Anesthesiology and Pain Medicine, Eulji University Hospital, Daejeon, Korea

Background: Dexmedetomidine, an $\alpha 2$-adrenergic agonist, can be used for sedation and as an adjuvant to anesthetics. This study aimed to evaluate the effects of preanesthetic administration of dexmedetomidine on the propofol and remifentanil requirement during general anesthesia and postoperative pain in patients undergoing laparoscopic cholecystectomy.

Methods: Sixty patients were randomly assigned to group D or S ( $\mathrm{n}=30$ each). Dexmedetomidine $(0.5 \mu \mathrm{g} / \mathrm{kg})$ and a comparable volume of saline were administered in groups $\mathrm{D}$ and $\mathrm{S}$, respectively, over a 10 minutes period before induction. General anesthesia was induced and maintained with propofol and remifentanil; the bispectral index was maintained at 40-60. The intraoperative remifentanil and propofol dosages were recorded, and postoperative pain was assessed using a visual analog scale (VAS)

Results: In groups S and D, propofol dosage was $8.52 \pm 1.64$ and $6.83 \pm 1.55 \mathrm{mg} / \mathrm{kg} / \mathrm{h}$, respectively $(P<0.001)$, while remifentanil dosage was $7.18 \pm 2.42$ and $4.84 \pm 1.44 \mu \mathrm{g} /$ $\mathrm{kg} / \mathrm{h}$, respectively $(P<0.001)$. VAS scores for postoperative pain were $6.50(6-7)$ and 6.0 (6-7), respectively, at 30 minutes $(P=0.569), 5(4-5)$ and $4(3-5)$, respectively, at 12 hours $(P=0.039)$, and $2(2-3)$ and $2(1.25-2)$, respectively, at 24 hours $(P=0.044)$. The Friedman test revealed that VAS scores changed over time in both groups $(P<0.001)$. Conclusions: Preanesthetic single administration of a low dose of dexmedetomidine $(0.5 \mu \mathrm{g} / \mathrm{kg})$ can significantly decrease the remifentanil and propofol requirement during short surgeries and alleviate postoperative pain.

Keywords: Anesthetics; Dexmedetomidine; Laparoscopic cholecystectomy; Propofol; Remifentanil.

\section{INTRODUCTION}

Dexmedetomidine, a selective $\alpha 2$ adrenergic receptor agonist, exerts its sedative and analgesic effects by activation of the locus coeruleus [1]. Contrary to other sedatives, it has fewer cardiovascular side effects and a lower risk of respira- tory depression. In addition, a decrease in the requirement of propofol [2,3], isoflurane [4,5], and desflurane [6] can be achieved with the use of dexmedetomidine during general anesthesia. Moreover, adjuvant dexmedetomidine administration has been shown to minimize postoperative nausea [7]. In general, the dosage of dexmedetomidine recommended

This is an Open Access article distributed under the terms of the Creative Commons Attribution Non-Commercial License (http://creativecommons.org/licenses/by-nc/4.0) which permits unrestricted non-commercial use, distribution, and reproduction in any medium, provided the original work is properly cited.

Copyright (C) the Korean Society of Anesthesiologists, 2019 
by the United States Food and Drug Administration is a loading dose of $1.0 \mu \mathrm{g} / \mathrm{kg}$ over 10 minutes, followed by continuous infusion at a dose of $0.2-1 \mu \mathrm{g} / \mathrm{kg} / \mathrm{h}$. However, beneficial effects have been reported with a single preoperative administration of a low dose of dexmedetomidine $(0.5 \mu \mathrm{g} /$ $\mathrm{kg}$ ); it aided sedation of patients [8] and resulted in fewer hemodynamic changes [9]. Moreover, Basar et al. [10] reported that it reduced thiopental requirements for the induction of anesthesia during cholecystectomy.

If the single administration of a low dose of dexmedetomidine without continuous infusion decreased total anesthetic requirements for both induction and maintenance, deep sedation during surgery could be achieved with a lower dosage of anesthetics. This study aimed to investigate the effects of preanesthetic administration of a single low loading dose of dexmedetomidine $(0.5 \mu \mathrm{g} / \mathrm{kg})$ without maintenance infusion on propofol and remifentanil requirements during general anesthesia in patients undergoing laparoscopic cholecystectomy. In addition, analgesic effects were evaluated by comparing postoperative pain scores to assess the effects of a single administration of dexmedetomidine on pain after surgery.

\section{MATERIALS AND METHODS}

This prospective, double-blind, placebo-controlled study was approved by the Institutional Review Board (IRB no. 2017-05-019) and adhered to the tenets of the Declaration of Helsinki. We initially evaluated patients scheduled for laparoscopic cholecystectomy under total intravenous anesthesia at our institution and selected 60 patients (age, 20-60 years) with an American Society of Anesthesiologists physical status of I-II for the present study. The study's purpose was explained to all the patients and consent was obtained. Pregnant patients and those with heart disease, liver disease, renal disease, pulmonary disease, and/or a history of allergy to the anesthetic drugs were excluded. A computerized random number generator was used to randomly assign the 60 patients to one of the following two groups: group D $(n=30)$, in which patients received dexmedetomidine before the induction of anesthesia, and group S $(n=30)$, in which patients received saline before the induction of anesthesia.

After the patient arrived in the operating room, electrocardiography, pulse oximetry, noninvasive blood pressure mea- surement, and bispectral index (BIS ${ }^{\mathrm{TM}}$, A-2000 BIS monitor, Aspect Medical System, USA) measurement were performed at 5-minutes intervals. Dexmedetomidine (Precedex, Hospira Inc., USA) was diluted in $0.9 \%$ normal saline to achieve a concentration of $4 \mu \mathrm{g} / \mathrm{ml}$ in a $50-\mathrm{ml}$ syringe. The same volume of $0.9 \%$ normal saline was prepared in a $50-\mathrm{ml}$ syringe. After the baseline heart rate was measured, the prepared dexmedetomidine $(0.5 \mu \mathrm{g} / \mathrm{kg})$ and $0.9 \%$ normal saline $(0.125 \mathrm{ml} / \mathrm{kg})$ solutions were administered over 10 minutes to the patients in groups $\mathrm{D}$ and $\mathrm{S}$, respectively.

Anesthesia was induced with $2 \%$ propofol (Fresofol $2 \%^{\mathrm{TM}}$, Fresenius Kabi, Austria) and remifentanil (Ultiva ${ }^{\circledR}$, Glaxo Smith Kline, UK) administered at effect-site concentrations of $5 \mu \mathrm{g} / \mathrm{ml}$ and $3 \mathrm{ng} / \mathrm{ml}$, respectively, using a target-controlled infusion (TCI) pump (Orchestra Base Primea ${ }^{\circledR}$, Fresenius Vial, France) under inhalation of $100 \%$ oxygen at $5 \mathrm{~L} / \mathrm{min}$. After the loss of the eyelid reflex, rocuronium $(0.5 \mathrm{mg} / \mathrm{kg})$ was administered.

The patients' lungs were ventilated with $100 \%$ oxygen for 2 minutes, followed by endotracheal intubation with a cuffed tube. During surgery, the effect-site concentration of propofol was adjusted by $0.5 \mu \mathrm{g} / \mathrm{ml}$ to maintain a $\mathrm{BIS}^{\mathrm{TM}}$ of $40-60$. The effect-site concentration of remifentanil was adjusted by 2 $\mathrm{ng} / \mathrm{ml}$ when the change in the heart rate was $>20 \%$ relative to the baseline rate. During mechanical ventilation, the endtidal carbon dioxide tension was maintained at $35-45 \mathrm{mmHg}$. An intra-abdominal pressure of $12-14 \mathrm{mmHg}$ was maintained throughout the surgery.

Surgery was considered complete when the surgeon placed the last suture. Subsequently, remifentanil and propofol infusion was discontinued, and pyridostigmine (0.2 $\mathrm{mg} / \mathrm{kg}$ ) and glycopyrrolate $(0.2 \mathrm{mg} / 5 \mathrm{mg}$ of pyridostigmine $)$ were administered. Extubation was performed when regular self-respiration was observed, and the patient responded to verbal commands. The time from the end of surgery to extubation was recorded. During surgery, atropine $(0.01 \mathrm{mg} / \mathrm{kg})$ was administered when bradycardia, defined as $<45$ beats/ min, occurred. Ephedrine ( $5 \mathrm{mg}$ ) was administered when the mean blood pressure was $<50 \mathrm{mmHg}$.

Postoperative pain was assessed using a visual analog scale (VAS), with a score of 1 indicating no pain and a score of 10 indicating the worst pain imaginable, at 30 minutes and 12 and 24 hours after surgery. If the VAS score was $\geq 6$ in the postanesthesia care unit, approximately $1 \mu \mathrm{g} / \mathrm{kg}$ of fentanyl 
was administered. No additional analgesics were given in the general medical ward, and no patient received patientcontrolled anesthesia (PCA).

All data were analyzed using IBM SPSS Statistics for Macintosh, Version 24.0 (IBM Corp., USA). A retrospective power analysis was performed using $G^{*}$ Power for Macintosh, version 3.1.9.3 (Heinrich-Heine-Universität Düsseldorf, Germany). The Shapiro-Wilk test was performed to test the variables for normality, and Student's $t$-test was used to compare the age, body mass index, height, weight, duration of anesthesia, duration of surgery, and duration from the end of surgery to extubation between groups S and D. A chi-squared test was used to compare categorical variables. Median VAS scores for postoperative pain were compared between the two groups using the Kruskal-Wallis test. The Friedman test was used to compare VAS scores among the different time points in each group, and a post hoc Wilcoxon signed-rank test with Bonferroni correction was performed to assess changes in VAS scores from 30 minutes to 12 hours and from 12 to 24 hours after surgery. Data are expressed as means \pm SDs, medians (interquartile range, 25-75\%), or numbers. A $\mathrm{P}$ value of less than 0.05 was considered statistically significant.

A power analysis was performed to estimate the appropriate sample size to determine a $20 \%$ or greater difference in anesthetic requirements between the two groups with $80 \%$ power and a 5\% level of significance. The estimated mean and standard deviation of propofol dosage for the main-

Table 1. Demographic Data, American Society of Anesthesiologists Physical Status, Duration of Anesthesia, Duration of Surgery, and Duration from the End of Surgery to Extubation for Patients Who Underwent Laparoscopic Cholecystectomy with or without Preanesthetic Administration of a Single Loading Dose of Dexmedetomidine

\begin{tabular}{|c|c|c|c|}
\hline Variable & $\begin{array}{l}\text { Group S } \\
(n=30)\end{array}$ & $\begin{array}{l}\text { Group D } \\
(n=30)\end{array}$ & $P$ value \\
\hline Age (yr) & $41.2 \pm 8.4$ & $37.6 \pm 9.8$ & 0.130 \\
\hline $\operatorname{Sex}(M / F)$ & $11 / 19$ & $8 / 22$ & 0.400 \\
\hline Body mass index & $24.8 \pm 3.5$ & $25.3 \pm 3.5$ & 0.600 \\
\hline $\begin{array}{l}\text { American Society of } \\
\text { Anesthesiologists physical } \\
\text { status (I-II) }\end{array}$ & $28: 2$ & $29: 1$ & 0.550 \\
\hline Duration of anesthesia (min) & $62.0 \pm 12.7$ & $63.0 \pm 14.6$ & 0.770 \\
\hline Duration of surgery (min) & $41.4 \pm 9.8$ & $43.8 \pm 14.2$ & 0.450 \\
\hline $\begin{array}{l}\text { Duration from the end of } \\
\text { surgery to extubation ( } \mathrm{min} \text { ) }\end{array}$ & $8.2 \pm 10.9$ & $5.2 \pm 1.2$ & 0.140 \\
\hline
\end{tabular}

$\overline{\text { Values are presented as mean } \pm \text { SD or numbers. Group S: saline }}$ group, Group D: dexmedetomidine group. tenance phase of anesthesia was calculated [2,11-13]. The number of patients required for each group was 27 or greater; considering the possibility of $10 \%$ dropout, the number of subjects for each group was set at 30 .

\section{RESULTS}

\section{Patient characteristics and power of the study}

A total of 60 patients were included in the study. Patient characteristics are shown in Table 1.

\section{Comparison of propofol and remifentanil dos- ages between the two groups}

The standardized propofol dose in group S and D was 8.52 \pm 1.64 and $6.83 \pm 1.55 \mathrm{mg} / \mathrm{kg} / \mathrm{h}$, respectively $(\mathrm{P}<0.001)$, while the standardized remifentanil dose in group $\mathrm{S}$ and $\mathrm{D}$ was 7.18 \pm 2.42 and $4.84 \pm 1.44 \mu \mathrm{g} / \mathrm{kg} / \mathrm{h}$, respectively ( $<<0.001$, Fig. 1 ).

\section{Comparison of postoperative pain between the two groups}

The VAS scores at 30 minutes after surgery were not significantly different between the groups $\mathrm{S}$ and $\mathrm{D}(\mathrm{P}=0.569)$, whereas those at 12 and 24 hours exhibited significant differences ( $\mathrm{P}=0.039$ and 0.044 , respectively). The VAS scores for postoperative pain were 6.5 (6-7) and 6 (6-7), respectively,
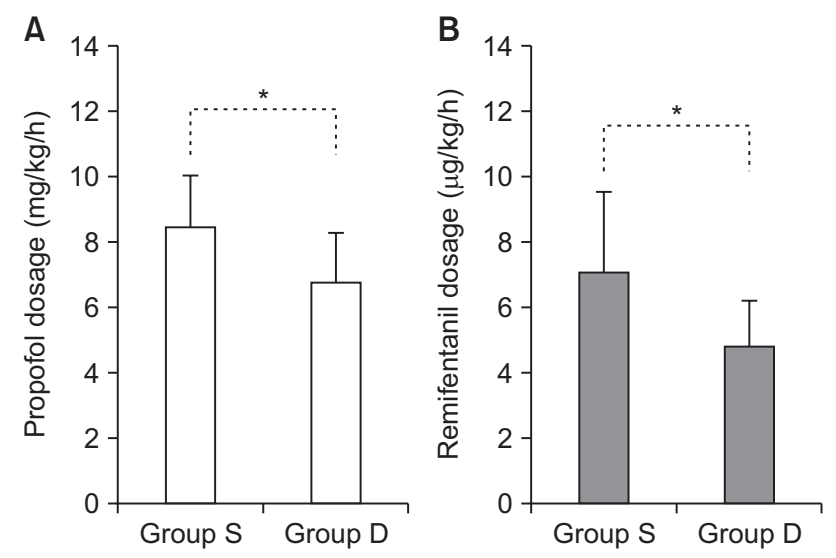

Fig. 1. Standardized dosages of propofol (A) and remifentanil (B) for patients who underwent laparoscopic cholecystectomy with or without preanesthetic administration of a single lading dose of dexmedetomidine. Group S: saline group, Group D: dexmedetomidine group. ${ }^{*} \mathrm{P}<$ 0.05 determined using Student's $t$-test. 
at 30 minutes ( $\mathrm{P}=0.569), 5(4-5)$ and 4 (3-5), respectively, at 12 hours $(\mathrm{P}=0.039)$, and $2(2-3)$ and $2(1.3-2)$, respectively, at 24 hours $(\mathrm{P}=0.044)$ (Fig. 2). In addition, the Friedman test revealed a significant decrease in the VAS score over time $(\mathrm{P}<0.001)$; post hoc tests showed that the VAS score significantly decreased from 30 minutes to 12 hours and from 12 to 24 hours after surgery in both the groups $(\mathrm{P}<0.001)$. The fentanyl doses are shown in Table 2; there was no significant difference between the two groups $(\mathrm{P}=0.768)$.

\section{DISCUSSION}

In the present study, we found that the preanesthetic administration of a single $0.5 \mu \mathrm{g} / \mathrm{kg}$ bolus of dexmedetomidine over 10 minutes before anesthesia induction decreased the amount of propofol and remifentanil required for maintaining general anesthesia. Although postoperative pain exhibited similar changes over time in groups $S$ (saline group) and $\mathrm{D}$ (dexmedetomidine group), dexmedetomidine helped in alleviating the postoperative pain.

Consistent with our findings, previous studies have demonstrated that the use of dexmedetomidine as an adjunct to anesthetics facilitates the lowering of anesthetics' concentration required during general anesthesia [2-5,14]. Dexmedetomidine decreases the minimum alveolar concentration (MAC) of isoflurane in a concentration-dependent manner, with a greater MAC-sparing effect at a plasma concentration

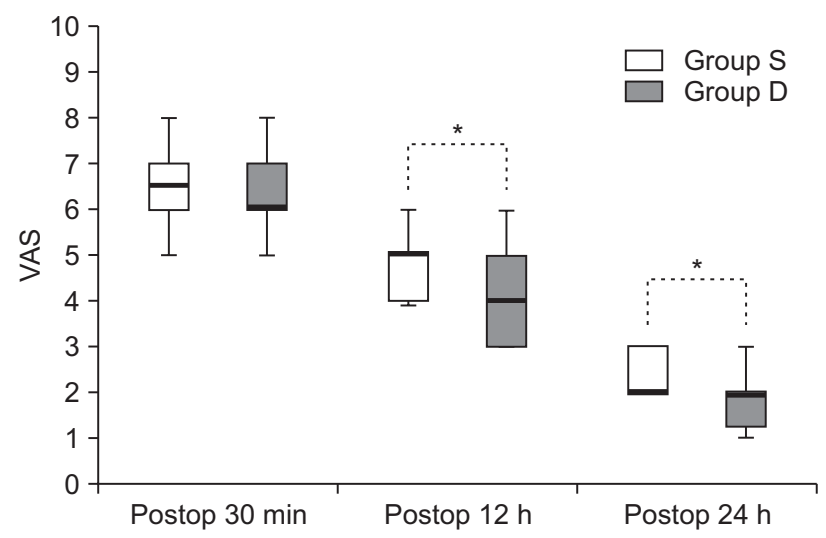

Fig. 2. Changes in postoperative pain over time in patients who underwent laparoscopic cholecystectomy with or without preanesthetic administration of a single loading dose of dexmedetomidine. Group S: saline group, Group D: dexmedetomidine group, VAS: visual analog scale, Postop: postoperative. ${ }^{*} \mathrm{P}<0.05$ determined using the Friedman test and a post hoc Wilcoxon signed-rank test with Bonferroni correction. of $0.35-0.75 \mathrm{ng} / \mathrm{ml}$ [4]. Moreover, administration of dexmedetomidine decreased the concentration of sevoflurane by $20-30 \%$ while maintaining a $\mathrm{BIS}^{\mathrm{TM}}$ of approximately 45 during lower abdominal surgery [5].

Dexmedetomidine decreases the concentration of propofol required for sedation and suppresses the motor response in healthy volunteers [3]; moreover, it decreases the amount of propofol required for achieving loss of consciousness when administered at the dose of $0.63 \mu \mathrm{g} / \mathrm{kg}$ [14]. Similar to our study, Le Guen et al. [2] reported that patients who received dexmedetomidine (a single loading dose of $1 \mu \mathrm{g} / \mathrm{kg}$ over 10 minutes, followed by continuous infusion of $0.5 \mu \mathrm{g} / \mathrm{kg} / \mathrm{h}$ throughout surgery) required $30 \%$ and $25 \%$ lesser amounts of propofol and remifentanil, respectively, for anesthesia induction; the required propofol dosage for the maintenance of anesthesia decreased by $29 \%$. However, the mean duration of anesthesia was 540 minutes in their study, whereas it was as short as 60 minutes in the present study. We found that the propofol and remifentanil dosages were $19.8 \%$ and $32.5 \%$ lower, respectively, in patients who received dexmedetomidine than in those who received placebo; this was observed even in surgeries with short operation times.

For postoperative pain, we found no significant difference in the pain score at 30 minutes after surgery between groups S and D. However, pain scores at 12 and 24 hours after surgery were significantly different between the groups. Although our methodology was different, our findings are similar to the previous studies reporting that dexmedetomidine significantly decreased the analgesic requirement during the first 24 hours $[15,16]$. The Friedman test revealed a significant decrease in the VAS score over time $(\mathrm{P}<0.001)$; post hoc tests showed a significant decrease in the score from 30 minutes to 12 hours and from 12 to 24 hours after surgery in both the

Table 2. Postoperative Fentanyl Use in PACU for Patients Who Underwent Laparoscopic Cholecystectomy with or without Preanesthetic Administration of a Single Loading Dose of Dexmedetomidine

\begin{tabular}{cccc}
\hline Variable & $\begin{array}{c}\text { Group S } \\
(\mathrm{n}=30)\end{array}$ & $\begin{array}{c}\text { Group D } \\
(\mathrm{n}=30)\end{array}$ & P value \\
\hline $\begin{array}{c}\text { Patients who received } \\
\text { fentanyl } \\
\text { Fentanyl dose }(\mu \mathrm{g})\end{array}$ & 23 & 25 & 0.526 \\
\hline
\end{tabular}

Values are presented as numbers or mean \pm SD. PACU: postanesthesia care unit, Group S: saline group, Group D: dexmedetomidine group. $P$ value from Student's $t$-test. 
groups.

Conversely, dexmedetomidine may result in hypertension, hypotension, and bradycardia. Thus, caution is required. These side effects are observed in a concentration-dependent manner, and the largest decrease in the blood pressure, and heart rate and cardiac output relative to the baseline value have been reported as 27 and 17\%, respectively [9,17]. Highdose administration of dexmedetomidine has the potential to induce hypotension via peripheral vasoconstriction due to the activation of the peripheral $\alpha_{2 B}$ adrenergic receptors.

This study has some limitations. First, the TCI pump was manually controlled by an anesthesiologist on the basis of BIS $^{\mathrm{TM}}$ values; therefore, propofol and remifentanil dosages may have been directly or indirectly influenced by the anesthesiologist's preferred dosage, any concomitant drugs used, and any accompanying diseases. In addition, the administration of dexmedetomidine may have resulted in an electroencephalogram similar to that obtained during physiological sleep [18]; this may have influenced $\mathrm{BIS}^{\mathrm{TM}}$ measurements in the group D. In turn, determination of the amount of anesthetic required, based on BIS $^{\mathrm{TM}}$ values, may have been affected. Second, intravenous PCA for postoperative pain was not used for any patient in the present study, so we could not compare PCA usage with regard to postoperative pain assessments. Further studies are necessary to overcome these limitations.

In conclusion, the findings of the present study suggest that the single administration of a low dose of dexmedetomidine $(0.5 \mu \mathrm{g} / \mathrm{kg}$ ) before short surgeries (within 1 hour), such as laparoscopic cholecystectomy, can decrease the remifentanil and propofol requirement for induction and maintenance of general anesthesia during surgery and can alleviate postoperative pain.

\section{CONFLICTS OF INTEREST}

No potential conflict of interest relevant to this article was reported.

\section{ORCID}

Han Park: https://orcid.org/0000-0002-9872-313X

Heung Soo Kim: https://orcid.org/0000-0001-7057-5174

Jae Won Kim: https://orcid.org/0000-0002-7256-6930
Gang Geun Lee: https://orcid.org/0000-0002-1703-2303

Dong Ho Park: https://orcid.org/0000-0002-6587-3756

Chang Young Jeong: https://orcid.org/0000-0003-2810-2511

Sun Gyoo Park: https://orcid.org/0000-0001-6235-6377

\section{REFERENCES}

1. Gertler R, Brown HC, Mitchell DH, Silvius EN. Dexmedetomidine: a novel sedative-analgesic agent. Proc (Bayl Univ Med Cent) 2001; 14: 13-21.

2. Le Guen M, Liu N, Tounou F, Augé M, Tuil O, Chazot T, et al. Dexmedetomidine reduces propofol and remifentanil requirements during bispectral index-guided closed-loop anesthesia: a double-blind, placebo-controlled trial. Anesth Analg 2014; 118: 946-55.

3. Dutta S, Karol MD, Cohen T, Jones RM, Mant T. Effect of dexmedetomidine on propofol requirements in healthy subjects. J Pharm Sci 2001; 90: 172-81.

4. Khan ZP, Munday IT, Jones RM, Thornton C, Mant TG, Amin D. Effects of dexmedetomidine on isoflurane requirements in healthy volunteers. 1: Pharmacodynamic and pharmacokinetic interactions. Br J Anaesth 1999; 83: 372-80.

5. Ohtani N, Kida K, Shoji K, Yasui Y, Masaki E. Recovery profiles from dexmedetomidine as a general anesthetic adjuvant in patients undergoing lower abdominal surgery. Anesth Analg 2008; 107: 1871-4.

6. Feld JM, Hoffman WE, Stechert MM, Hoffman IW, Ananda RC. Fentanyl or dexmedetomidine combined with desflurane for bariatric surgery. J Clin Anesth 2006; 18: 24-8.

7. Blaudszun G, Lysakowski C, Elia N, Tramèr MR. Effect of perioperative systemic $\alpha 2$ agonists on postoperative morphine consumption and pain intensity: systematic review and metaanalysis of randomized controlled trials. Anesthesiology 2012; 116: $1312-22$

8. Kim JW, Lee HL, Park JS, Kim JH, Ryu KH. Pre-anesthetic sedative effects of dexmedetomidine in laparoscopic cholecystectomy performed under general anesthesia. Anesth Pain Med 2018; 13: 23-9.

9. Aantaa R. Assessment of the sedative effects of dexmedetomidine, an alpha 2-adrenoceptor agonist, with analysis of saccadic eye movements. Pharmacol Toxicol 1991; 68: 394-8.

10. Basar H, Akpinar S, Doganci N, Buyukkocak U, Kaymak C, Sert O, et al. The effects of preanesthetic, single-dose dexmedetomidine on induction, hemodynamic, and cardiovascular parameters. J Clin Anesth 2008; 20: 431-6.

11. Luo D, Wan X, Liu J, Tong T. Optimally estimating the sample mean from the sample size, median, mid-range, and/or mid- 
quartile range. Stat Methods Med Res 2018; 27: 1785-805.

12. Wan X, Wang W, Liu J, Tong T. Estimating the sample mean and standard deviation from the sample size, median, range and/or interquartile range. BMC Med Res Methodol 2014; 14: 135.

13. Hozo SP, Djulbegovic B, Hozo I. Estimating the mean and variance from the median, range, and the size of a sample. BMC Med Res Methodol 2005; 5: 13.

14. Peden CJ, Cloote AH, Stratford N, Prys-Roberts C. The effect of intravenous dexmedetomidine premedication on the dose requirement of propofol to induce loss of consciousness in patients receiving alfentanil. Anaesthesia 2001; 56: 408-13.

15. Unlugenc H, Gunduz M, Guler T, Yagmur O, Isik G. The effect of pre-anaesthetic administration of intravenous dexmedeto- midine on postoperative pain in patients receiving patientcontrolled morphine. Eur J Anaesthesiol 2005; 22: 386-91.

16. Venn RM, Bradshaw CJ, Spencer R, Brealey D, Caudwell E, Naughton C, et al. Preliminary UK experience of dexmedetomidine, a novel agent for postoperative sedation in the intensive care unit. Anaesthesia 1999; 54: 1136-42.

17. Bhana N, Goa KL, McClellan KJ. Dexmedetomidine. Drugs 2000; 59: 263-8.

18. Huupponen E, Maksimow A, Lapinlampi P, Särkelä M, Saastamoinen A, Snapir A, et al. Electroencephalogram spindle activity during dexmedetomidine sedation and physiological sleep. Acta Anaesthesiol Scand 2008; 52: 289-94. 